\title{
TEORIA DAS REPRESENTAÇÕES SOCIAIS E CIÊNCIAS SOCIAIS: trânsito e atravessamentos
}

\author{
Angela Arruda*
}

Resumo: Este texto pretende assinalar a relação da teoria psicossocial das representações sociais de Serge Moscovici com as ciências sociais, a partir da sua caracterização como uma abordagem de interpenetração da Psicologia com a Sociologia. Primeiramente fará uma breve análise sobre o trânsito entre Psicologia-Psicologia Social e Ciências Sociais, como um dos elementos de explicação para o entrecruzamento da Teoria das Representações Sociais (TRS) com as ciências sociais. Em seguida pontuará como este entrecruzamento se coloca na abordagem moscoviciana, e como a TRS não escapa a ele. $\mathrm{O}$ argumento da autora é de que a base da relação entre essas áreas e a TRS está na concepção do social, presente no pensamento moscoviciano, o qual, ao mesmo tempo, não negligencia o quanto os aspectos psicológicos participam dos fatos sociais. $\mathrm{O}$ texto se encerra com alguns exemplos de pesquisa para ilustrar esta posição.

Palavras-chave: teoria das representações sociais; ciências sociais; atravessamentos.

O estudo sobre a representação social da Psicanálise na França dos anos 50, de como ela se tornou um fato da cultura (Moscovici, 1961), persegue a transformação do pensamento social e os seus desdobramentos segundo o grupo que fala. Ou seja, como todo tipo de saber especializado, uma vez posto em debate na esfera pública, tornava-se objeto de representação, migrando do seu universo específico para o do senso comum. Levar adiante esta empreitada

\footnotetext{
* Doutora em Psicologia Social pela Universidade de São Paulo (USP); professora do Programa de Pós- Graduação em Psicologia da Universidade Federal do Rio de Janeiro (UFRJ).E-mail: arrudaa@centroin.com.fr
} 
significou produzir a Teoria das Representações Sociais (TRS) a partir de um entrecruzamento de ciências.

A passagem de um saber do seu próprio domínio para o mundo da conversação entre os leigos é um fenômeno psicossocial. Envolve a mobilização de elementos psicológicos - afetivos, cognitivos, imaginários, fantasmáticos, de memória e outros - mas impregnados de conteúdo social - sociológico, histórico, cultural, linguístico, entre outros - e acontece ao mesmo tempo nesses dois registros que se encontram totalmente entrelaçados: o social e o individual, dissolvendo assim a dicotomia indivíduo-sociedade. $\mathrm{O}$ dilema do ovo e da galinha, para efeitos do trabalho do pensamento, fica superado, uma vez que quem pensa está inserido e atravessado pela sociedade (com sua história, forma de organização, suas culturas etc.). Moscovici (1988) cita Lévi-Strauss para apoiar essa inseparabilidade:

[...] é bem verdade que, em certo sentido, todo fenômeno psicológico é um fenômeno sociológico, o mental se identifica com o social. Mas, num outro sentido, tudo se inverte. A prova do social só pode ser mental; ou seja, nós jamais poderemos estar seguros de ter atingido o sentido e a função de uma instituição se não formos capazes de reviver a sua incidência sobre uma consciência individual. Como essa incidência é uma parte integrante das instituições, qualquer interpretação deve fazer coincidir a objetividade da análise histórica ou comparativa com a subjetividade da experiência vivida.

Na busca moscoviciana da compreensão da mudança, portanto, se indivíduo e sociedade não se separam, mas se atravessam, nem a Psicologia nem as ciências sociais - entre as quais ele situa a Psicologia Social - podem explicá-la sozinhas. Esta é uma vertente da Psicologia que vê a Psicologia social como área de interface ciência charneira, segundo Maisonneuve ([1950] 1988, p. 129), encruzilhada, "entre a Antropologia Cultural, a Sociologia, a Psicologia e a Psiquiatria". Podemos acrescentar também a História (e se enveredamos pelas artes, a literatura, o cinema, as artes plásticas, a fotografia e a música...). 
É nesta perspectiva que se integra o pensamento moscoviciano, toda a sua obra, bem como a de Jodelet. Nos tempos de hoje, podemos ir além e supor que, mais que uma encruzilhada, estamos falando de uma aliança que se assemelha àquela discutida por Prigogine e Stengers (1997), da qual eles apontam Moscovici como um dos precursores. Ela implica - por entender o social e o individual como fios entrelaçados num mesmo tecido -, considerar esse tecido de forma aberta e múltipla, sem barreiras disciplinares. A teoria que aqui está em pauta se situa no coração dessa aliança, ao navegar sempre no encontro das águas da Psicologia Social e suas irmãs, as outras ciências sociais.

Pretendo aqui caminhar no sentido de assinalar a relação da TRS com as ciências sociais a partir da sua caracterização como uma abordagem de interpenetração da Psicologia com a Sociologia. Proponho, então, desenvolver o texto passando primeiro por uma breve análise sobre o trânsito entre Psicologia-Psicologia Social e ciências sociais, como um dos elementos de explicação para o entrecruzamento da TRS com as ciências sociais. Em seguida, pontuarei como este entrecruzamento se coloca na abordagem moscoviciana, e como a não escapa dele. Minha posição é de que a base da relação entre essas áreas e a TRS está na concepção do social, presente no pensamento moscoviciano, o qual, ao mesmo tempo, não negligencia o quanto aspectos psicológicos participam dos fatos sociais. Encerrarei com alguns exemplos de pesquisa para ilustrar esta posição.

\section{Psicologia, Psicologia Social, Ciências Sociais}

A Psicologia Social - como Moscovici e Jodelet a entendem - é uma ciência social. Contudo, a contribuição desses dois autores mais conhecida entre nós, a Teoria das Representações Sociais (TRS), despertou questionamentos que variaram de "o que tem a ver 
com ciência social?" até "em que difere da abordagem sociológica?" É fácil respondermos que o interesse pelos processos psicossociais de elaboração das representações enfatizando suas raízes sociais é o nó da questão, embora isto não seja tudo. A representação social, na abordagem daqueles autores, nada tem a ver com o reflexo da realidade. Teoriza, avant la lettre, em 1961, a perspectiva da construção social da realidade, que será sistematizada por Berger e Luckmann pouco tempo depois, em 1963.

Tal construção social acontece atravessada por um fluxo de afetos, imaginários, estilos cognitivos e se configura por meio de processos que, sendo sociais, são ao mesmo tempo psicológicos, como aqueles que permeiam a produção das representações sociais, tal como consideram Moscovici e Jodelet. Refiro-me aqui aos processos de objetivação, ancoragem, focalização, pressão à inferência, dispersão da informação. Ou seja, processos que, do ponto de vista psicossocial, estão entre os que contribuem para a mudança do pensamento social e, simultaneamente, são formas de organização do pensamento social e operações mentais. Esse atravessamento, contudo, não era ponto pacífico quando Moscovici interpelou a Psicologia Social, situando-a como ciência social.

\section{A Psicologia e as Ciências Sociais}

Para entender como se coloca no campo da Psicologia a relação entre TRS e ciências sociais, é interessante revisitar rapidamente a relação entre a Psicologia- em particular a Psicologia Social e aquelas ciências. ${ }^{1}$ Foi o que fizeram recentemente Moscovici e Markova (2006), quando propuseram a existência de duas tradições da área e batizando-as como a tradição de origem americana (indigenous american, no original) e a tradição euro-americana. Alertando para a simplificação inevitável desse tipo de classificações, sinalizam que suas grandes diferenças são epistemológicas. A 
primeira filia a Psicologia Social à Psicologia geral como área mãe, devido à ênfase comum às duas: a natureza humana tal como se expressa no indivíduo. Em algumas interpretações, isto significa uma aproximação com as ciências neurológicas, uma vez que os processos psicológicos (memória, percepção, etc.) se produzem de forma semelhante nos indivíduos graças ao funcionamento do cérebro. Só o indivíduo tem cérebro, não a multidão ou o grupo. Isto afasta as ciências sociais, estranhas ao treinamento dos psicólogos; eles se aproximam mais das práticas experimentais em laboratório, isoladas da realidade. O que o laboratório faz, nesta vertente, é criar situações artificiais e um grupo fictício que não funciona amparado em nenhum contexto, a não ser o do próprio experimento. Os autores estabelecem uma metáfora, da ciência-porta e da ciênciaponte. Esta tradição se situaria na primeira, fechando-se para teorias sociológicas ou antropológicas.

Em contraste, a tradição euro-americana considera que a Psicologia Social vem preencher uma lacuna entre a Antropologia Cultural e a Sociologia. Com efeito, ela se encontrava no departamento de ciências sociais de muitas universidades americanas. Kurt Lewin chegava a considerar que ciências como a Sociologia ou a Psicologia deveriam ficar à vontade para recorrer a construtos de outras ciências se estas se adequassem às questões com as quais elas lidavam. E recomendava que, para ter idéias, não se lesse Psicologia, mas sim Filosofia, História, Ciência, poesia, romances e biografias. Assim, a Psicologia Social nesta tradição seria uma ciência-ponte, porque recorre à interdisciplinaridade não apenas para combinar conhecimentos de várias disciplinas sobre um assunto, mas porque "constrói conhecimento novo sobre um tema específico usando o conhecimento de outras áreas" (Moscovici; Markova, 2006, p. 40). Isso teria acontecido no estudo de fenômenos como a influência social, a inovação e a conformidade.

A diferença fundamental entre as duas tradições seria a concepção e o lugar do 'social': na tradição de origem americana, 
o grupo seria um agregado de indivíduos, enquanto que na euroamericana, o grupo, ou a cultura, implica interdependência, dinâmica interna - homeostase e interação, um sistema vivo feito de forças interativas que buscam um equilíbrio. O emblema de cada uma seria, respectivamente, o conceito de atitude e o de grupo social. Moscovici e Markova (2006) exemplificam ainda com teóricos importantes de cada uma, Floyd Allport e Kurt Lewin, entre outros.

Esta interpretação da história da Psicologia Social, situando-a em vertentes que se entrecruzam, uma das quais a coloca na seara das ciências sociais, parece avançar um pouco mais com relação àquela expressa por Farr (1994), que separava a Psicologia Social psicológica e a sociológica quase como duas entidades existentes na realidade, e não como fruto de uma angulação da história da Psicologia. Ademais, as duas tradições não se sucedem, mas se entrelaçam. Ambas as leituras, contudo, coincidem no reconhecimento da "insularidade" da psicologia, como dizia Duveen, e insistem na existência de uma Psicologia Social que se filia e se mistura às ciências sociais. Ela confirma a posição da obra de Moscovici. Para além do grupo, existe a sociedade mais ampla, colocada no território da determinação central da representação. Jodelet (2001) sistematiza esta idéia ao explicitar a afirmação de Moscovici de que toda representação é representação de alguém e de alguma coisa, indicando que esse alguém integra pertenças sociais variadas, se situa num tempo histórico, numa sociedade dada, em um lugar dela que faz parte da forma como ela se organiza, e que o coloca em contato com formas de comunicação, institucionalidades, ideologias, culturas específicas. Isto, nos estudos de representações sociais, é contemplado pelo estudo dos contextos (Jesuíno, 2001), os quais compõem uma espiral que vai do mais imediato, situacional, até o mais remoto, ligado ao passado histórico e ao imaginário coletivo (Arruda, 2005) 


\section{Moscovici: pensando a vida, a natureza, a sociedade}

A obra de Serge Moscovici se pauta pela interdisciplinaridade, já observada no seu extenso percurso de reflexão sobre a relação entre os humanos e a natureza, para além das teorias psicossociais que elaborou. Naquele percurso, não hesitou em dialogar com a Biologia, a Genética, a História, a Antropologia (Moscovici, 1972, 1977), mostrando como a relação entre a natureza e a humanidade tem uma complexidade que escapa à visão da dominação da natureza pelo homem. Da mesma forma, ele é responsável por uma teoria que vem contrariar tudo o que se estudava sobre influência social até então na Psicologia Social. A área se interessava sobretudo pela pressão à conformidade, pela influência da maioria, e a resistência à posição predominante era colocada no terreno do desvio. Moscovici propõe observar o problema pelo avesso: em contraposição ao interesse pela permanência, pela preservação da continuidade, toma o ângulo da mudança, no qual a inovação pode acontecer a partir da ação de minorias ativas. Os "desviantes" seriam, então, possíveis inovadores. Pensar o social sem divisórias disciplinares para pensar a mudança, é, portanto, uma marca da sua reflexão que se prolonga na TRS. Moscovici é tanto um psicólogo social quanto um pensador das questões da vida, do social e da natureza, como bem descreve o título do livro em sua homenagem (Buschini; Kalampalikis, 2001). Não poderia ser diferente, uma vez que, para ele, estas dimensões se interpenetram. O leque da interdisciplinaridade pode variar segundo a temática que ele traz à cena. No texto escrito com Markova (Moscovici; Markova, 2006, p. 39), sobre o qual se apoiou até aqui esta reflexão, ele retoma, ao analisar a construção da Psicologia Social moderna, o argumento de Lewin sobre ciências como a Sociologia ou a Psicologia, citado anteriormente.

Em suma, o fato de que a TRS seja uma teoria de interface ou de aliança - entre a Psicologia, a Sociologia e a Antropologia, já indica que nela, como no pensamento moscoviciano de forma geral, 
não se trata de um encontro fortuito ou complementar de disciplinas, mas de áreas cujo íntimo parentesco é incontornável para entender a produção do conhecimento tal como Moscovici propõe: deslindar a construção do pensamento cotidiano pelos seus múltiplos autores, encontrar os processos que estão na base da mudança do pensamento e das práticas sociais.

Falar em autores, ou atores, implica falar em suas várias inserções - social, histórica, política, cultural etc. E aqui o social se amplia, aumentando o foco progressivamente do close sobre o entorno imediato até atingir uma grande angular. Estas inserções compõem o acervo de onde surgirá a representação que qualquer grupo elabora; elas são reordenadas, negociadas, recortadas e recombinadas para configurar o pensamento. Sem conhecer as raízes do pensamento dos grupos e, por conseguinte, dos sujeitos - o que remete à sociedade como um todo e seus múltiplos recortes - torna-se impossível chegar à compreensão do seu processo de construção da realidade, de elaboração do conhecimento na vida diária. Fatores como a memória, a experiência, o olhar, cuja incidência para a produção das representações é fundamental, são multiface, situados tanto no espaço social quanto no individual. $\mathrm{O}(\mathrm{s})$ espaço(s) social(is) pelos quais cada um transita marcam-no, mas também é(são) tingido(s) pela sua tonalidade específica, fruto do encontro e da negociação das diversas procedências do pensar. É impossível negar o peso da comunicação, da troca, do confronto de idéias para produzir uma representação social. $\mathrm{O}$ ambiente pensante em que vivemos, nas sociedades contemporâneas, com a velocidade vertiginosa do fluxo de informações, estimula esta produção, porque é preciso falar do que todos falam, mostrar que se "está por dentro".

O ser humano, portanto, não pensa isolado, desligado do social. Ele pensa atravessado por este. Ele carrega no seu pensar a marca dos grupos que incidem sobre a sua experiência, sobre a sua identidade, bem como a marca da história, da política, das divisões 
sociais e tantas outras, e isso não se configura como uma simples retradução na linguagem daquele grupo. A invenção do pensamento no dia a dia mistura, portanto, elementos que envolvem interesses, exercício do poder, desejo de aceitação, eventuais questões circunstanciais, compondo um novo desenho traçado pelos diversos atravessamentos do social - os mais próximos, os mais distantes que vão da experiência vivida à necessidade de comunicação, de reconhecimento, passando pela presença ou pertença aos grupos sociais, valores e interesses do grupo, bem como pelo momento histórico, a posição sociocultural, geográfica, étnica, religiosa, até a situação política mais próxima e mais geral - não obrigatoriamente nesta ordem. Em ambos os casos, trata-se do "social"- mais, ou menos, encarnado - nas pessoas e nos grupos sociais que a atravessam e que ela atravessa, ou, como se costuma dizer, tanto no nível micro como no macro. As representações sociais seriam - para sintetizar e simplificar - uma forma de manejo do macro (entre outras coisas) no nível micro. Do ponto de vista psicossocial, elas trazem para o registro do cotidiano: relações, concepções, crenças, imagens e afetos que a sociedade abriga e veicula por períodos longos - e outros não tão longos - vertendo-os na construção deste cotidiano. Elas trabalham não apenas o que provoca o conhecimento, o objeto que instiga a (re)construção, mas os diversos fios que tecem a organização social, a urdidura das culturas, os andaimes do simbólico, para acolher na rede pré-existente de significados o objeto ou a situação que se apresenta.

A necessidade e relativa facilidade do diálogo da teoria das representações sociais com as ciências sociais, desta forma, não são circunstanciais, mas sim fator constitutivo da teoria: elas conferem a densidade e o caráter que ela possui. A TRS é uma abordagem de aliança, situada na fecundação entre a Psicologia e a Sociologia, em sintonia com o pensamento de Prigogine e Stengers (1997, p. 209), que o consideram um precursor da perspectiva da abertura das 
ciências à imprevisibilidade e ao diálogo com um mundo aberto, "ao qual pertencemos e em cuja construção colaboramos".

Como seus teóricos não cansam de afirmar, isso acontece a partir da visão da Psicologia Social como uma ciência social (Castro, 2002), e como conseqüência, porque a TRS vê o social como caleidoscópico - dotado de múltiplas facetas - e inseparável/ indistinguível do indivíduo ou, deveríamos dizer, no híbrido individuossociedade. Essa capilaridade permite hoje pensar o social recorrendo à metáfora do rizoma, que projeta raízes e caules em todas as direções, indistinguindo-o no corpo da teoria.

O projeto epistemológico que a teoria abraça, partindo do pressuposto da construção social da realidade, está na base dessa proposição. O fim das dicotomias, que faz parte dos eixos da teoria, estabelece o desbotamento da divisória indivíduo-sociedade, que se apresenta também sob a forma sujeito-objeto. Indivíduo e sociedade, sujeito e objeto, são duas formas de entender o comparecimento do humano frente a disjuntivas colocadas pela sua condição: mais do que duas faces da mesma moeda, são fios do mesmo tecido. Daí a impossibilidade de estudar representações sociais sem as ciências sociais. Os contextos nos quais nos situamos nos constituem, e é nesta condição de seres contextuados que elaboramos nossas representações. Isso implica um entendimento holográfico de pessoas, grupos e sociedade como um todo. Não se trata de acumular uma lista de pertenças que nos percorrem, mas de entendê-las como forma de expressão articulada e semovente da sociedade em que vivemos e da sociedade global: suas características contemporâneas, os interesses que a habitam, as posições que se aliam e se contrapõem, o complexo jogo jogado para a sobrevivência no planeta hoje, com suas características diversas e plásticas. A compreensão das grandes linhas diretoras e demarcadoras desta(s) sociedade(s), bem como da porosidade entre elas, e das resistências e alternativas a elas é indispensável para perceber como as pertenças das pessoas, 
atravessadas pelas características mais gerais da organização e funcionamento da sociedade se articulam e negociam entre si e, desta maneira, fazem a construção social da realidade. Em resumo, voltando ao vocabulário consagrado, para compreender o micro, é preciso conhecer o macro.

\section{Construindo conhecimento novo usando o conhecimento de outras áreas ${ }^{2}$}

A relação entre Psicologia e Sociologia é assunto de muitas discussões levadas a cabo por Moscovici. Depois de brigar no seio da sua própria área para mostrar a incontornável dimensão do social na Psicologia em A máquina de fazer deuses (1988), ele reage ao dogma anti-psicologista de que os fatos sociais não podem receber explicações psicológicas. Mostrando ao mesmo tempo a relação da Sociologia com a modernidade e o império da razão, advoga a impossibilidade de separar as coisas: dificilmente os fatos sociais podem ser analisados sem recorrer a noções psicológicas, e as teorias sociais recorrem a elas o tempo todo, mesmo sem reconhecer isso. Mais uma vez Moscovici se adianta, introduzindo o discurso sobre a falácia da modernidade e as armadilhas do racionalismo, insinuando o que Latour (1994) iria definir como hibridismo em Jamais fomos modernos. Ou seja, partindo do mesmo pressuposto da relação intrínseca entre individual e social, Moscovici ressalta ali a dimensão psicológica dos fatos sociais e das teorias que tratam de explicá-los.

Em texto recente, Porto (2009) traz considerações sobre as dimensões objetiva e subjetiva da violência e ressalta que, por um lado, o caráter objetivo do fenômeno define a sua concretude pela via dos registros e estatísticas, tornando-o "inegável”; por outro lado, o caráter subjetivo inclui o que diferentes indivíduos e sociedades reputam como violência, e esta representação pode interferir "na 
própria realidade da violência..." (p. 149). Em uma pesquisa em curso, que coordeno, sobre o universo do funk proibido no Rio de Janeiro com jovens moradores de espaços populares, alguns deles comentaram durante a entrevista que se sentem mais seguros nos bailes funk na comunidade que frequentam do que em bailes "de pista", comerciais, porque conhecem as pessoas, e sobretudo porque lá o tráfico impede que haja confusão - o fuzil faz as vezes de segurança, ainda que não seja esta a sua função primordial naquele momento. O subjetivo é parte da substância do social, jogando sobre ele uma luz que pode nos surpreender, iluminando-o por outros ângulos.

Como esclarece Porto (2009), o caráter quase tangível que podem ter as representações sociais, segundo Moscovici, pode torná-las/tomá-las como realidade concreta, o que reafirma o poder das crenças, tendo sido o motivo da busca teórica desse autor a partir da experiência de vida sob o nazismo, confrontado pela crença então circulante na superioridade ariana. No exemplo acima, o fuzil objetivaria a presença do tráfico no baile. Como um de seus emblemas, ele é ao mesmo tempo prestígio e perigo, conferindo aos meninos que o carregam, uma aura que os transforma aos olhos das meninas - e da população em geral. Mas não obrigatoriamente transmite o sentimento de temor e insegurança associado à violência em toda situação. Pelo contrário, nesses testemunhos, ele é identificado como um elemento protetor, mostrando que, além de uma representação hegemônica que o associa à violência, existe uma situação, um lugar e um segmento em que ele pode não ser visto sob este ângulo.

[...] é possível supor que existam, por um lado, contextos (objetivos) mais ou menos favoráveis ao desenvolvimento da violência, e que, por outro, o que é representado como violência (dimensão subjetiva) 'participe' igualmente da realidade da violência. Se determinados contextos favorecem o desenvolvimento de manifestações de violência, essa, uma vez posta em ação, manifesta aos atores o poder de sua utilização. Nesse sentido, uma violência que, inicialmente, se 
constitui a partir de um contexto propício produz, ou pode produzir, a violência como lógica de intervenção. O que está em questão não é algo como o círculo vicioso da violência, mas o fato (...) de serem objetividade e subjetividade dois elementos interagindo solidariamente na constituição do fenômeno. (Porto, 2009, p. 149150)

A partir da indicação de Porto, trago o exemplo de uma pesquisa sobre imaginário e representações sociais do Brasil por jovens universitários (Arruda; Ulup, 2007) para ilustrar as ciências sociais entrelaçadas na TRS, trazendo a configuração do pensamento social como a trama em que pertenças e influências sociais de variados níveis se configuram num desenho específico daquele grupo, que revela como estas influências são atravessadas por afetos e formas de saber também específicas. Como afirma Thiesse (2001), uma nação é resultado de um longo processo de construção histórica, cultural, social e política, processo esse que institui um imaginário e um sentimento de nacionalidade, os quais se expressam por meio da elaboração de um conjunto de representações sociais. Um país existe tanto na sua materialidade concreta quanto nas mentes e nos afetos das pessoas. Desta forma, compreender a visão que tem dele os futuros profissionais implica percorrer as suas representações sociais.

\section{Brasil, brasis: as representações sociais de jovens universitários}

O Projeto "Imaginário e Representações Sociais do Brasil e da Escola" situa-se na vertente dos poucos trabalhos de Psicologia Social voltados para o pensamento brasileiro a respeito da nação e dos seus cidadãos, de Manoel Bomfim a Dante Moreira Leite e até hoje. Uma das questões que conduziu a pesquisa foi de investigar o que seria o Brasil para jovens iniciantes de cursos universitários, em pleno processo de globalização liberal, nos anos 2003-4 (Arruda; 
Ulup, 2007). ${ }^{3}$ Foi utilizada a metodologia dos mapas mentais, inspirada no trabalho de Milgram e Jodelet (1976) sobre os mapas de Nova York e Paris.

Participaram 1.029 jovens das cinco regiões do Brasil, estudantes do primeiro ano de cinco cursos universitários: Enfermagem, Serviço Social, Pedagogia, Medicina e Engenharia. Inicialmente, desenharam um mapa do Brasil com o que imaginavam encontrar-se aí; deviam explicar o que tinham desenhado e responder duas perguntas abertas: o que fazia com que tudo aquilo fosse Brasil e o que diferenciava o Brasil de outros países. Depois, outros mapas deviam ser preenchidos com indicações sobre aspectos culturais, históricos, econômicos da renda, etc. Ao final, deviam completar frases iniciadas com o gentílico de cada Estado brasileiro, como: cearense é...; gaúcho é... etc. Para ilustrar o que anunciei acima, vou pinçar alguns resultados referentes apenas ao desenho do primeiro mapa. Parte desses resultados corresponde ao conjunto de 1.029 mapas e outra parte provém de trabalhos de mestrado realizados por jovens pesquisadoras do projeto. Num deles, foram analisados 140 mapas de estudantes do Rio de Janeiro (Cruz, 2006) e no outro, 177 do Pará (Gonçalves, 2008).

$\mathrm{Na}$ totalidade dos 1.029 mapas, alguns elementos chamaram a atenção pela sua constância. O primeiro foi a ausência de países para além das nossas fronteiras: o único limite externo, quando havia, era o mar. O contraste com pesquisa similar, levada a cabo no México (Guerrero, 2007), sugere o peso de circunstâncias políticas, sociais e culturais de cada país sobre a maneira como é construído - ou imaginado - por seus habitantes (Anderson, 1989). Os jovens mexicanos desenham uma fronteira com os Estados Unidos demarcada por muros, barreiras, armas, mulheres mortas e até uma pirâmide, inexistente na região. Já ao sul, com países da América Central a divisória é quase ausente. $\mathrm{O}$ desenho expressa uma situação de fato com relação a estas duas fronteiras, tingida 
pelo colorido da sua representação social: a divisa sob a forma de muro, que inexistia naquele momento, mas já estava presente no imaginário dos jovens. Da mesma maneira o registro das mortes de mulheres em Juárez, talvez como uma objetivação da violência ressentida pelos mexicanos naquela região, em relação com o vizinho do norte. A presença da pirâmide na fronteira, que não é um dado de realidade, nos provoca a suposição de que, como um dos emblemas da nação, ela demarca o território e sinalizaria a riqueza ao sul do Rio Grande - as tradições culturais mexicanas, apesar do trânsito em busca do sonho americano. No sul do México, por sua vez, o que se vê é uma continuidade entre o México e os demais países de língua espanhola.

Quanto ao Brasil, aparece como um país sem vizinhos, solto no espaço, cuja fronteira apenas o contém, fechado sobre si mesmo. Só o mar indica o contato com o exterior, como uma reminiscência do período da colônia. Com efeito, em pesquisa sobre a memória do descobrimento do Brasil, levada a cabo no momento do $5^{\circ}$ Centenário, a imagem mais associada a ele foi a das caravelas (Sá. Oliveira; Prado, 2005), sublinhando o mar como a via de chegada e saída. O Brasil começa no mar. Em nossa pesquisa, a imagem de um país descolado do continente domina a folha de papel, havendo até desenhos em que ele aparece cercado de água por todos os lados, ocupando todo o espaço da América do Sul. Podemos nos perguntar até que ponto a visão que a escola difunde não seria a maior fonte de inspiração para este tipo de figuração, e acompanharia a afirmação de Capelato (2000) a respeito do proverbial desinteresse dos brasileiros pelos outros países latino-americanos, relacionado à falta de um projeto unificador da América Latina que envolvesse o Brasil e fosse ao mesmo tempo político e identitário. Cabe também se perguntar o que acontece com esta representação social quando a região é valorizada pela política externa brasileira, traz benefícios econômicos e ganha maior visibilidade e interesse do público. 
O outro limite, a oeste, mostra um Centro-Oeste definido nos mapas pela incompletude. Às vezes, totalmente em branco, às vezes com a ilustração do Distrito Federal isolada no meio do nada. Muitos afirmam desconhecer o que existe na região. Impossível não se remeter à antiga representação, surgida no Brasil Colônia. Segundo Amado (1995), o interior, ou sertão, denotava "terras sem fé, nem lei nem rei”: áreas extensas, longe do litoral, de natureza selvagem; as autoridades detinham pouca informação ou controle sobre elas. Aparentemente, a Marcha para o Oeste não se concretizou na representação dos estudantes: apenas Brasília tem registro nela. $\mathrm{O}$ restante do Centro-Oeste continuaria como no passado: um grande território desocupado (Gonçalves, 2008).

Por fim, no que se refere ao conjunto dos estudantes, cabe ressaltar que o desenho do Brasil contém figuras que retratam repetidamente os seus problemas, numa visão crítica, mais, ou menos, acentuada segundo fatores que veremos mais adiante.

Esses elementos anunciam um pouco do que interessa para esta discussão: a conjugação dos contextos - possibilitada pela Sociologia, as ciências políticas, a História, a Geografia indispensável para a compreensão do que dizem os estudantes por meio dos desenhos, e do olhar psicossocial, pelo qual transitam, além da força das crenças e graças ao poder da imagem, o lugar dos vazios, a cor, a expressão dos afetos e os atalhos da identidade, tonalizando visões não generalizantes do país.

Outro exemplo desse olhar é o que se observou a partir do que os geógrafos denominam "fator de proximidade" (Saarinen, 1973), segundo o qual o lugar de origem e adjacências tem maior probabilidade de serem desenhados num mapa feito de memória; como são mais conhecidos, aparecem com mais detalhe e proporções aumentadas. Isto se confirmou em uma parte dos mapas, porém ficou claro que a proximidade geográfica não dá origem a um simples estoque de conhecimentos, mas é atravessada por afetos, que podem 
se expressar no apego ao lugar, num sentimento de território, que vai além da mera demarcação espacial (Giménez, 2000), chegando a compor uma marca de identidade.

Passo então ao que têm em comum os estudantes paraenses e cariocas, a partir dos dados de Gonçalves (2008) e Cruz (2006). Para começar, dois elementos de estruturação dos mapas: a forma e a lógica de organização. A forma do país para ambos é próxima à dos mapas oficiais e ao que se vê nos manuais escolares, porém com as características já comentadas de um grande espaço pairando sem raízes sobre a folha branca. Quanto à organização dos conteúdos, ela segue duas lógicas: uma regional, que distribui os desenhos em consonância com as regiões geográficas, respeitando o que rezam os manuais escolares, e outra desterritorializada, em que os desenhos não guardam correspondência com o lugar onde são colocados, podendo indicar características gerais do país, como "uma casa, um lar... porque o Brasil é o nosso lar..." (estudante de Pedagogia, Rio de Janeiro), ou "panela vazia... porque existe muita fome e miséria" (estudante de Pedagogia, Pará). A distribuição dessas lógicas é praticamente a mesma nos dois Estados: entre dois terços e três quartos dos mapas são desterritorializados, sendo o restante regionalizado. Na verdade, essas duas lógicas recobrem duas visões do Brasil: uma apoiada na diversidade das regiões e a outra no que é característico do País como um todo (Cruz, 2006). Contudo, ambas são atravessadas por uma avaliação dos seus componentes, tendendo a ressaltar positivamente os aspectos naturais, por um lado, e, por outro, a arrolar uma série de problemas socioeconômicos, evidenciando mais um contraste estruturante do País, desta vez entre natureza e sociedade.

No Pará, a lógica desterritorializada corresponde aos cursos de Serviço Social e Pedagogia, enquanto a regionalizada, aos cursos de Engenharia e Medicina. Quanto aos elementos desenhados, os alunos de Medicina deram maior destaque aos elementos naturais, 
enquanto os de Serviço Social, aos elementos humanos, apontando para aspectos vinculados às respectivas carreiras como terreno de ancoragem.

Igualmente comum é a dupla visão do Sul. Por um lado, ela é minimalista, o que não se expressa verbalmente, mas sim graficamente: em vários mapas ele aparece espremido, reduzido, ou sem a presença do mar, ou ainda sem nenhum conteúdo desenhado, podendo combinar mais de um desses aspectos (Fig. 1 e 2). Por outro lado, há desenhos que sublinham a sua diferença com o resto do Brasil por meio do clima frio, da população de origem européia, da menor desigualdade e maior democracia.

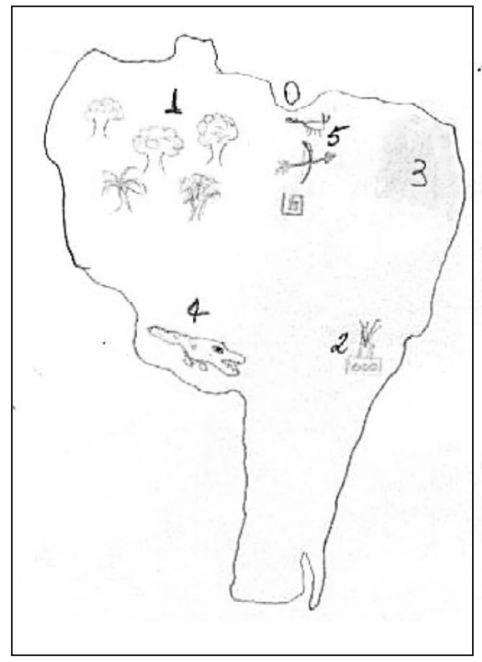

Figura 1 - Sul minimizado

- Estudante de Engenharia

- Estado do Pará

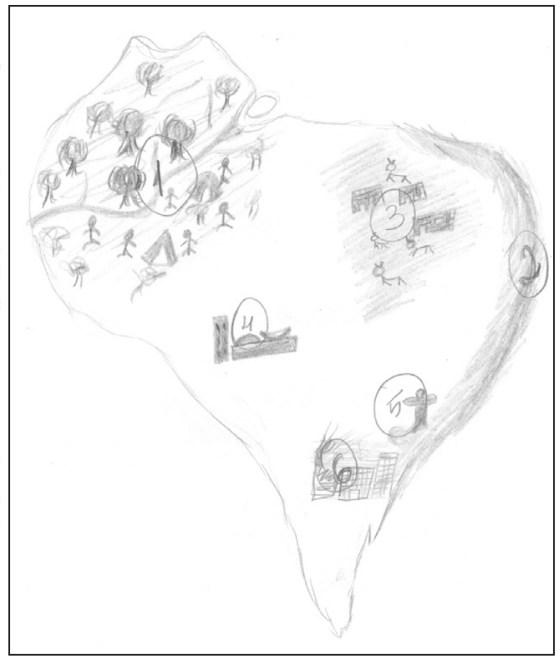

Figura 2 - Sul minimizado - Estudante de Serviço Social Estado do Rio de Janeiro

A floresta amazônica, último rincão da vida selvagem, última fronteira de mata virgem, tem grande presença nos mapas dos paraenses e cariocas, e, para ambos, é riqueza natural sob risco de extinção; mas, entre eles, há nuances. Os estudantes paraenses, mais numerosos a desenhá-la, apresentam uma visão mais próxima, quase vivencial. Ela constitui para eles, ao mesmo tempo, um 
ecossistema integrado por rios e matas, fonte de biodiversidade e de minérios, e um espaço que se revela num cotidiano específico, com crianças que vão à escola de barco, por exemplo, além de ser um símbolo da nacionalidade. Outra nuance se refere à beleza da floresta, "símbolo de beleza e uma fonte de vida" (estudante de Pedagogia, PA), que só é mencionada pelos paraenses. $\mathrm{O}$ fator de proximidade parece se confirmar e se revestir também das tintas da identidade; isso corresponderia às praias do Rio de Janeiro, que foram superlativizadas pelos estudantes desse Estado. A natureza, portanto, mantém-se firme no ranking do imaginário dos dois grupos de universitários, por vias diversas.

O território nacional estaria, assim, delimitado segundo uma visão singular dos pontos cardeais: a leste, pelo mar; ao norte, pela floresta; a oeste, por um espaço opaco ou fracamente identificado, finalizando ao sul com um espaço reduzido ou marcado pela imagem de "Um Brasil diferente" (Martins, 2005) que sistematiza o imaginário sobre essa parte do País (Oliveira, 2007). Tal distribuição acaba por desenhar o Brasil como a conjugação litoral-interior, tendo este um triplo desdobramento: a mata, o campo e o sertão, localizado na Região Nordeste.

A representação hegemônica, como denomina Moscovici (1988), é o que mais se aproxima, na tradução na TRS, da representação coletiva conceituada por Durkheim: o Brasil está cercado de natureza por todos os lados, guardando ainda aparentemente a definição de país de riquezas naturais privilegiadas. Porém, esta representação, que nos acompanha desde a carta de Caminha, não é tão uniforme nem tão inescapável quanto parece. $\mathrm{O}$ estudo dos mapas mostrou como, a respeito desse mesmo objeto o Brasil -, convivem representações hegemônicas e representações sociais específicas de grupos ou segmentos, no caso, estudantes de regiões diferentes e até de cursos diferentes. 


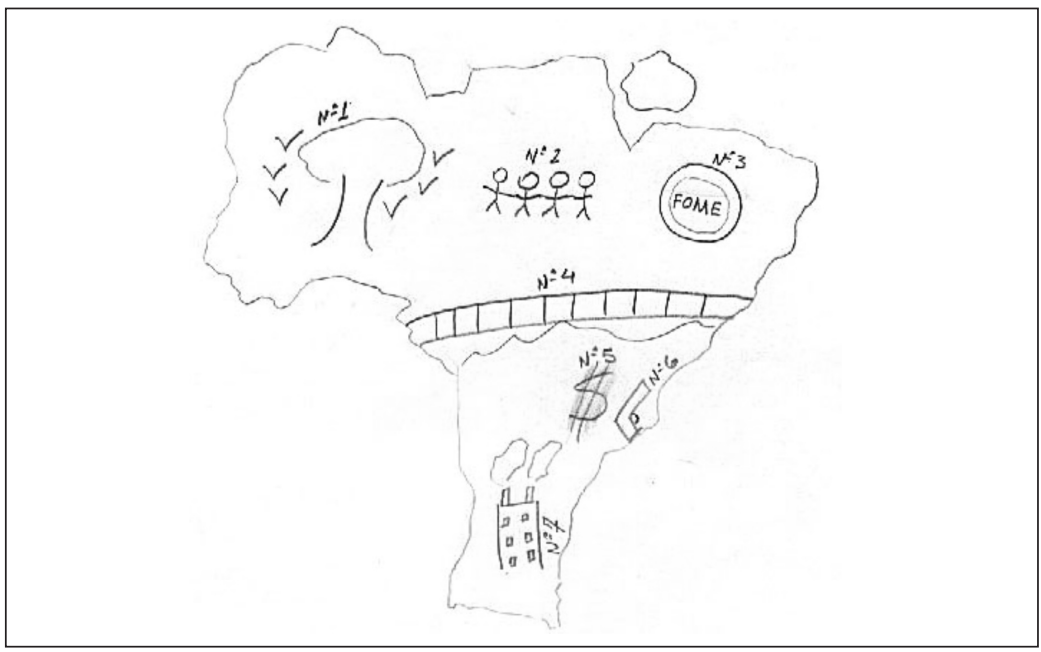

Figura 3 - Brasil dividido - Estudante de Engenharia - Estado do Pará

Neste sentido, chamam a atenção de imediato, entre os desenhos feitos no Pará, aqueles que dividem o Brasil em dois Norte e Sul - seja por meio de uma linha demarcatória, uma barreira, ou um espaço em branco, seja pela disposição dos desenhos no interior dos mapas. Embora não sejam a maioria, eles mostram uma diferença sobretudo nas formas da riqueza: acima, a riqueza natural; abaixo, a riqueza financeira, simbolizada pelo cifrão, por exemplo. O contraste é uma das formas de estruturação dos mapas e da representação do Brasil, de modo geral, e não faltam indicadores para confirmá-lo, mas o que é intrigante é o registro de uma 'barreira física' (Gonçalves, 2008, p.75) que parece objetivá-lo e remete à história das relações entre a Província do Grão Pará e o resto do Brasil. Os universitários expressaram indignação pela não participação nas riquezas produzidas na região - "um lugar de riquezas, mas excluído do Brasil" (estudante de Engenharia, PA) - e pela destruição da floresta. O presente parece reforçar a possível "memória coletiva [que suscitou] uma predisposição significante que resultou em mapas separados" (Gonçalves, 2008, p.76), à semelhança dos mapas 
de Paris recolhidos por Milgram e Jodelet (1976), que apresentavam às portas da cidade a barreira dos fazendeiros (fermiers généraux), desaparecida no século XVIII.

Ainda sobre a possível permanência da representação do Brasil como paraíso terrestre pela sua natureza, fica claro que, embora a imagem idealizada continue a ser evocada, não se trata mais de uma natureza intocada. O desmatamento, as queimadas, a soja, na Região Norte, e a poluição e a urbanização desordenada, na Região Sudeste, revelam que a visão da natureza tem dois lados: o do desejo (ou será do clichê?) que a instituiu em símbolo do Brasil, marca identitária, ancorada no passado, e o do conflito na realidade do tempo presente, com as conseqüências do progresso e das políticas, desembocando em problemas, alguns semelhantes e outros específicos para cada região. A violência, por exemplo, tem a ver com o tráfico de drogas e a miséria no Rio de Janeiro. Já no Pará, está presente sobretudo nos conflitos agrários, na luta pela terra, na fronteira com a Colômbia. A sensibilidade aos problemas, por sua vez, apresenta diferenças entre os cursos, no Pará. Os estudantes de Serviço Social manifestamse mais sobre os socioeconômicos, enquanto os de Medicina e Engenharia, sobre os relativos à natureza.

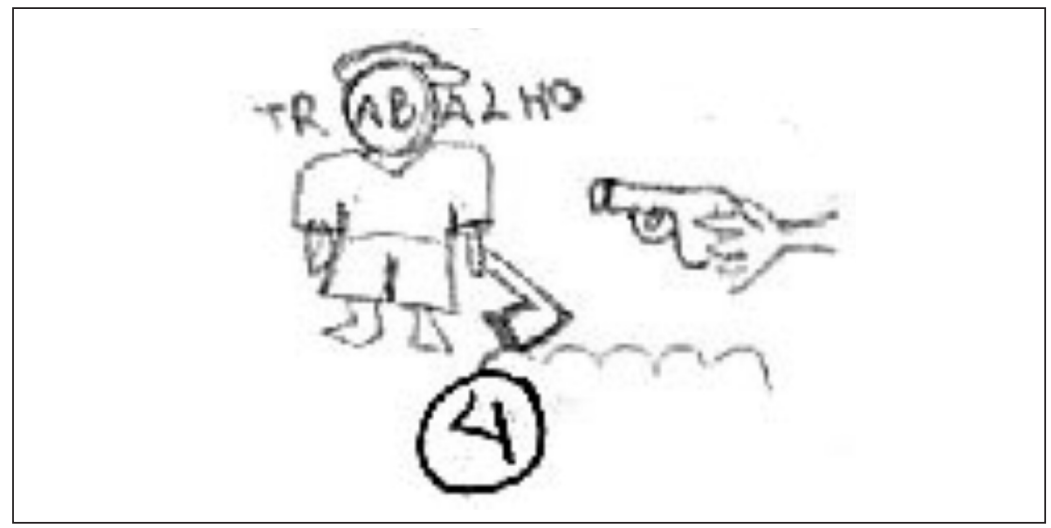

Figura 4 - Cenas de violência - Estudante de Enfermagem Estado do Pará 


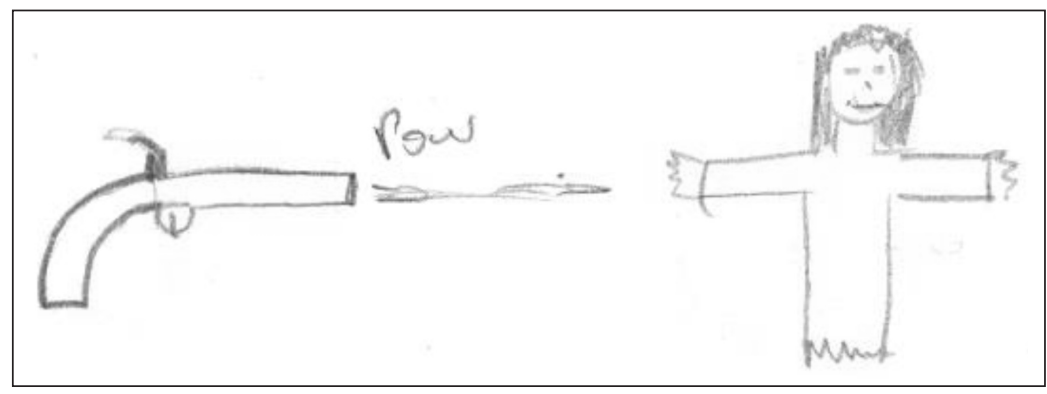

Figura 5 - Cenas de violência -

Estudante de Pedagogia - Estado do Rio de Janeiro

\section{Últimas palavras}

Após estes exemplos, fica claro que aí comparecem tanto a memória coletiva - remetendo a fatos e crenças originados na nossa história - quanto o peso da estrutura econômica e social do Brasil e as políticas que a sustentam, com os problemas e conflitos que provocam. Os estudantes mostraram em seus mapas, ademais, uma visão que exprime o olhar situado no contexto geográfico e cultural deles. Por último, para entender a maneira como o Brasil é imaginado por eles, não se pode contornar o seu atravessamento pelos afetos. O exemplo dos paraenses é feliz para mostrar o entrelaçamento do social e do psicológico. O sentimento de distância, exclusão e espoliação que vários deles expressam denuncia o lugar de onde falam, e parece ser o produto tanto dos dados de realidade relativos à exploração dos recursos naturais da Amazônia quanto da herança de uma história complicada das relações entre o Pará e o resto do Brasil. Desta forma, se a história, a política, a economia esclarecem a origem de mitos e crenças que ainda se manifestam quanto ao Brasil, a representação social do país integra aí também a Sociologia, o tempo presente, vivido e veiculado pelas instituições produtoras de subjetividade, como a escola e os meios de comunicação, num tecido bem urdido e denso, entremeado dos afetos que este conjunto de fatores ajudou a criar. A representação social do Brasil é um 
amálgama de várias camadas de pensamentos e afetos, originadas em contextos e momentos diversos da existência do país.

Por fim, ressalto ainda o fato de que, mesmo se um país é, como acredita Anderson (1989), uma comunidade imaginada, a sua representação se relaciona também com práticas, tanto aquelas que difundem a representação oficial, como as educativas e as que implementam as políticas públicas, quanto aquelas exercidas pelas populações que o habitam. Os estudantes do Rio de Janeiro falam de práticas da vida urbana na metrópole litorânea, práticas de lazer, de sociabilidade, experiências que lhes são familiares e que informam o seu olhar. O mesmo acontece com os paraenses, a partir de outras práticas e experiências, como as da vida ribeirinha. O olhar informado recorre, assim, à experiência, às representações hegemônicas, aos conhecimentos prévios para elaborar a representação social. Esta, uma vez delineada, entra em jogo como uma rede de significados que se torna manejável, ajudando a situar-se no mundo, e a falar do Brasil. Mas também ajuda a agir a partir dessa representação. Mas isso já seria assunto para outro artigo.

Resumindo, para ressaltar a concepção de social que habita a abordagem psicossocial da teoria das representações sociais, o social aqui não é um elemento de circunstância, uma variável no processo de representar. Ele está embutido em todo o processo, porque ele é constitutivo do humano e do pensar. Ele é dotado de uma dimensão rizomática, na medida em que tanto contempla a interação imediata, face a face, entre os humanos, quanto as bases da formação social que permeiam os humanos, e é difícil deslindar essas esferas, a não ser em termos conceituais, uma vez que a própria interação face a face carrega as marcas sociais, históricas, culturais e outras de quem nela participa, ainda que boa parte disto não seja consciente. Esta concepção do social, que Oliveira (2003) requeria da TRS, tem-na tornado efetiva para a reflexão sobre inúmeros problemas trazidos pelas áreas aplicadas da Saúde, da Educação, e, agora, também de outras que vão se aproximando dela. 
A teoria psicossocial das representações sociais não se considera uma teoria acabada. Na sua concepção, já Moscovici a definiu como uma teoria aberta para permitir que a complexidade do seu objeto pudesse receber o tratamento necessário, o que, por si só, é um processo longe de se encerrar. Ela se desenvolveu bastante em quase meio século de existência, gerando até vertentes diferenciadas. A mudança, o Graal da teoria, contudo, cobra a busca incessante. A proximidade e o diálogo com as outras ciências sociais é parte desse processo.

\title{
Notas
}

1 Para uma discussão a respeito da Psicologia Social e Sociologia, remeto a Sá (1998) e sobre a relação entre Sociologia e representações sociais, a Doise (1986), Jodelet (2009) e Porto (2009), não sem antes retomar algumas reflexões de Moscovici (1988) e Moscovici e Markova (2006) sobre o encontro (e desencontros) dessas duas áreas.

2 Tomo emprestada aqui a idéia de Moscovici e Markova (2006, p. 40) para caracterizar a interdisciplinaridade, mencionada anteriormente.

3 Projeto "Imaginário e Representações Sociais do Brasil e da Escola", realizado no quadro do grupo de trabalho Imaginários Latinoamericanos, do Laboratório de Psicologia Social, Maison des Sciences de l'Homme, Paris, com financiamento da Fapesp, Fundação Carlos Chagas, apoio da Fundação José Bonifácio (UFRJ) e bolsas de iniciação científica CNPq. O projeto executado no Brasil foi levado a cabo também no México, com o mesmo instrumento e público semelhante.

Theory of social representations and social sciences: transit and crossings

\begin{abstract}
This text intends to pinpoint the relationship between the psychosocial theory of social representations by Serge Moscovici and the social sciences, based on the characterization of this theory as an interpenetrative approach between psychology and sociology.
\end{abstract}


Firstly, the transit between psychology-social psychology and sociology will be briefly presented as one of the elements that explain the intertwining of the Theory of Social Representations (TSR) and social sciences. Next, it will be indicated how this intertwining is present in Moscovici's approach and how the TSR cannot escape it. The author's argument is that the relationship between these two fields is based on the conception of the social in Moscovici's thought, which does not neglect the importance of psychological aspects for social facts as well. The text concludes with some examples of research works that illustrate this point of view.

Keywords: theory of social representations; social sciences; crossings.

\section{Referências bibliográficas}

AMADO, J. Região, sertão, nação. Estudos Históricos, v. 8, n. 5, p.145151, 1995.

ANDERSON, B. Nação e consciencia nacional. São Paulo: Ática, 1989.

ARRUDA, A. Despertando do pesadelo: a interpretação. In: MOREIRA, A. S. P.; CAMARGO, B. V.; JESUINO, J. C.; NÓBREGA, S. M. Perspectivas teórico-metodológicas em representações sociais. João Pessoa: Universitário UFPB, 2005. p. 229-258.

ARRUDA, A.; ULUP, L. Brasil imaginado: representaciones sociales de jóvenes universitarios. In: ARRUDA, A.; DE ALBA, M. (Coords.) Espacios imaginários y representaciones sociales: aportes desde Latinoamérica. Barcelona: Anthropos, UAM, 2007. p. 165-198.

BUSCHINI, F.; KALAMPALIKIS, N. Penser la vie, le social, la nature: mélanges en l'honneur de Serge Moscovici. Paris: Editions de la Maison des Sciences de l'Homme, 2001.

CAPELATO, M. H. O "gigante brasileiro" na América Latina: ser ou não ser latino-americano. In: MOTA, Carlos Guilherme (Org.). Viagem incompleta: a experiência brasileira (1500-2000). São Paulo: Senac, 2000 . 
CASTRO, Paula. Notas para uma leitura da teoria das representações sociais em S. Moscovici. Análise Social, Revista do Instituto de Ciências Sociais da Universidade de Lisboa, v. 37, n. 164, p. 949979, 2002.

CRUZ, A. C. D. Representações sociais de universitários do Rio de Janeiro sobre o Brasil. 2006. Dissertação (Mestrado em Psicologia) - Universidade Federal do Rio de Janeiro (UFRJ), 2006.

DOISE, W. Les représentations sociales: définition d'un concept. In: DOISE, W.; PALMONARI, A. (Orgs.). L'étude des représentations sociales. Neuchâtel: Delachaux et Niestlé, 1986. p. 81-94.

FARR, R. Representações sociais: a teoria e sua história. In: JOVCHELOVITCH, S.; GUARESCHI, P. (Orgs.) Textos em representações sociais. Petrópolis: Vozes, 1994. p. 31-59.

GIMÉNEZ, G. Territorio, cultura e identidades: la región sócio-cultural. In: ROSALES, R. (Org.). Globalización y regiones en México. México: UNAM-Fcps-PUEC-Miguel Angel Porrúa, 2000. p. 19-52.

GONÇALVES, L. P. V. Um país escorre pelas terras dos rios gigantes: representações sociais de universitários do Pará sobre o Brasil. 2008. Dissertação (Mestrado em Psicologia) - Universidade Federal do Rio de Janeiro (UFRJ), 2008.

GUERRERO, A. Imágenes de América Latina y México a través de los mapas mentales. In ARRUDA, A.; ALBA, M. de (Orgs.). Espacios imaginarios y representaciones sociales: aportes desde Latinoamérica. Barcelona: Anthropos, 2007. p. 235-284.

JESUINO, J. C. Ancrages. In: BUSCHINI, F.; KALAMPALIKIS, N. Penser la vie, le social, la nature: mélanges en l'honneur de Serge Moscovici. Paris: Editions de la Maison des Sciences de l'homme, 2001. p. 267-291.

JODELET, D. Representações sociais. Rio de Janeiro: Eduerj, 2001. . Recentes desenvolvimentos da noção de representações sociais nas ciências sociais. In: ALMEIDA, A. M. O.; JODELET, D. (Orgs.). 
Interdisciplinaridade e diversidade de paradigmas: representações sociais. Brasília: Thesaurus, 2009. p. 105-122.

LATOUR, B. Jamais fomos modernos. São Paulo: Editora 34, 1994.

MAISONNEUVE, J. A psicologia social. Trad. Álvaro Cabral. São Paulo: Martins Fontes, [1950] 1988.

MARTINS, W. Um Brasil diferente: ensaio sobre fenômenos de aculturação no Paraná. São Paulo: T. A. Queiroz, [1955] 1989.

MILGRAM, S.; JODELET, D. Psychological maps of Paris. In: PROSHANSKY, H.; ITTELSON, W.; RIVLIN, L. (Eds.) Environmental psychology: people and their physical settings. New York: Holt, Rinehart \& Winston, 1976. p. 104-124.

MOSCOVICI, S. La représentation sociale de la psychanalyse. Paris: PUF, 1961.

. La société contre nature. Paris: Union Générale d’Éditions, 1972.

. Essai sur l'histoire humaine de la nature. Paris: Flammarion, 1977.

. A máquina de fazer deuses. Trad. Maria de Lourdes Menezes. Rio de Janeiro: Imago, 1988.

MOSCOVICI, S.; MARKOVA, I. The making of modern social psychology. The hidden story of how an international social science was created. Cambridge: Polity Press, 2006.

OLIVEIRA, M. Imigração e diferença em um estado do sul do Brasil: o caso do Paraná. Nuevo Mundo Mundos Nuevos v. 7, 2007. Disponível em: $\quad<$ http://nuevomundo.revues.org/index5287.html\#tocto1n3>. Acesso em: em 17 out. 2009.

PORTO, M. S. G. Re-pensando crenças e valores: sociologia e representações sociais. In: ALMEIDA, A. M. O.; JODELET, D. (Orgs.). Interdisciplinaridade e diversidade de paradigmas: representações sociais. Brasília: Thesaurus, 2009. p. 139-161. 
PRIGOGINE, I.; STENGERS, I. A nova aliança. Brasília: Ed. UnB, 1997.

SÁ, C. P. Psicologia social e ciências sociais. Cadernos de Psicologia, UERJ, Rio de Janeiro, n. 8, p. 7-17, 1998.

SÁ, C. P.; OLIVEIRA, D. C.; PRADO, L. A. As memórias coletivas do descobrimento do Brasil: imagem comum e juízos diferenciados nas populações portuguesa e brasileira. In: SÁ, C. P. de; CASTRO, P. (Orgs.). Memórias do descobrimento do Brasil. Rio de Janeiro: Museu da República, 2005. p. 27-44.

SAARINEN, T. Students views of the world. In: DOWNS, R.; STEA, D. (Orgs.). Image and environment: cognitive mapping and spatial behavior. Chicago: Adline Publishing, 1973. p. 148-161.

THIESSE, A. M. La création des identités nationales: Europe XVII-XX siècle. Paris: Seuil, 2001. 